\title{
Villegagnon: Herói ou vilão?
}

Vasco MARIZ*

Resumo: Villegagnon é um dos personagens mais massacrados de nossa história colonial. $\mathrm{O}$ motivo foi a freqüente reedição do livro Viagem à Terra do Brasil, de Jean de Léry, e da História dos Mártires, de Jean Crespin, entre os historiadores. Villegagnon é o vilão. Recentemente, em 1991, o historiador naval Leonce Peillard publicou em Paris o livro intitulado Villegagnon, Vice-amiral de Bretagne et Vice-roi du Brésil (Edições Perrin), que apresenta convincentes pesquisas recentes, explica e absolve Villegagnon das acusações dos calvinistas. Depois disso, a Marinha brasileira decidiu homenagear Villegagnon e, em 2000, o embaixador do Brasil na França instalou um obelisco feito com pedras da ilha em sua cidade natal de Provins, perto de Paris. $\mathrm{O}$ almirante francês é considerado por muitos historiadores como o verdadeiro fundador do Rio de Janeiro, e não Estácio de Sá, que só chegou à Guanabara onze anos depois.

Palavras-Chave: Villegagnon; Colonização Francesa; Estácio de Sá.

Villegagnon é um dos personagens mais massacrados de nossa história. A principal causa desse curioso fenômeno foi a freqüente reedição ao longo dos séculos do livro Viagem à Terra do Brasil, de Jean de Léry, e a repercussão da pequena História dos Mártires, de Jean Crespin entre os historiadores. Pela

\footnotetext{
* Jornalista, editor, escritor e Secretário Geral da Association Dialogue France-Brésil. Em 2000, publicou "Villegagnon ou a utopia tropical" com prefácio de Jean-Christophe Ruffin, uma obra que retrata a efêmera epopéia da França Antártica. E-mail: vasco.mariz@globo.com
} 
primeira vez publicado em Paris, em 1578, o livro de Léry agradou imensamente pela pitoresca e pormenorizada descrição do Brasil quinhentista. Villegagnon é o vilão. Recentemente, em 1991, o historiador naval francês Leonce Peillard publicou em Paris um excelente livro intitulado Villegagnon, Vice-amiral de Bretagne et Vice-roi du Brésil (Edições Perrin), que apresenta valiosas pesquisas recentes, explica e absolve Villegagnon de muitas acusações dos calvinistas, que pesavam sobre a sua imagem histórica há mais de quatro séculos.

Villegagnon era originário da pequena nobreza francesa, nascido em 1510, na cidade de Provins, a $80 \mathrm{~km}$ de Paris, na região hoje tão conhecida dos famosos queijos Brie. Teve ótima formação universitária em Paris e Orleans e na rigorosa Ordem de Malta, atuando primeiramente como correio diplomático do rei Francisco $1^{\circ}$. Depois combateu na Itália, onde se adestrou no manejo das armas da época até ser destacado para acompanhar a esquadra do imperador Carlos $\mathrm{V}$ em seu projetado ataque a Argel. A frota imperial era imensa e deveria ser bem sucedida, não fosse uma terrível tempestade que dispersou as naus e deixou isolados em terra boa parte dos soldados imperiais. Os sarracenos contra-atacaram e Villegagnon, à frente dos cavaleiros de Malta, bateu-se denodadamente diante dos muros da cidade e acabou ferido no braço esquerdo por um golpe de lança. Carlos V assistiu de perto a bravura de Villegagnon e o confortou com palavras de agradecimento, e até mesmo o legado do Papa escreveu ao rei Francisco $1^{\circ}$ louvando o feito de Villegagnon. Esse episódio lhe seria de muita utilidade no futuro, pois por duas vezes ele recorreu ao imperador, que se recordava dele com simpatia e sempre atendeu a seus pedidos. $\mathrm{Na}$ época, Villegagnon escreveu um pequeno livro em latim, relatando a expedição de Carlos V a Argel.

No entanto, Villegagnon só ficou famoso na Europa pelo seqüestro de Maria Stuart, a futura rainha da Escócia, que o rei Henrique II da França queria para noiva de seu filho menor, depois Francisco II. Já os ingleses protestantes ambicionavam a menina para rainha da Inglaterra, com o objetivo de incorporarem a Escócia católica. Villegagnon comandava quatro 
galeras e, em vez de se dirigir diretamente à costa leste do país, conseguiu burlar o bloqueio da esquadra inglesa dando a volta à ilha pela Irlanda e norte da Escócia, atravessando mares turbulentos. Chegou à foz do Clyde e subiu o rio até a fortaleza de Dumbarton, onde estava refugiada Maria Stuart. Embarcou a menina de cinco anos e o seu séquito e regressou pela mesma difícil rota, chegando a um pequeno porto francês perto de Brest. Dias depois, ela era recebida com toda a pompa pelo rei Henrique II no castelo de Saint Germain-en-Laye, nos arredores de Paris. Se Villegagnon tivesse fracassado e a menina capturada pelos ingleses, a história da Europa no século XVI poderia ter sido bem diferente. $O$ rapto foi sensacional e os ingleses foram humilhados. O futuro almirante tinha 38 anos apenas.

Destacou-se depois na defesa de Malta, sede da sua Ordem, e com apenas um punhado de cavaleiros reforçou as defesas da ilha e conseguiu afugentar a esquadra turca que pretendia apossar-se da ilha. Até hoje podemos visitar, na velha capital M'Dina, a Villegagnon Street, homenagem de agradecimento do povo maltês pela sua defesa da ilha 450 anos atrás. Pouco depois, ele recebeu o título de Vice-almirante da Bretanha das mãos do rei Henrique II e sua próxima missão foi a de fortalecer o porto de Brest, cujas defesas estavam mal conservadas e vulneráveis a ataques de corsários ingleses e espanhóis.

O almirante, em sua carreira militar, teve a proteção pessoal direta de quatro reis de França, isto é: de Francisco $1^{\circ}$, Henrique II, Francisco II e Carlos IX, além da rainha regente Catarina de Médicis e também do imperador Carlos V, cuja vida Villegagnon havia diretamente defendido no malogrado cerco de Argel. Além disso, pelo seu preparo intelectual, Villegagnon era escritor, falava várias línguas e foi amigo pessoal de dois dos mais importantes poetas franceses da época, Rabelais e Ronsard, que escreveu um poema em seu louvor, chamando-o de douto. Portanto, ele não era um aventureiro desalmado como pintaram os calvinistas, ávido de ouro e sangue, como seus contemporâneos Pizarro e Cortéz nas Américas. 
Villegagnon começou a pensar no Brasil em Brest, onde conversava com marinheiros que regressavam de viagens à América do Sul. Em Dieppe e Honfleur, ele teria encontrado com André Thevet e Hans Staden que estiveram em nosso país e ouviu também os grandes armadores normandos e bretões donos das naus que faziam o comércio tão lucrativo com o Brasil. Em 1554, Villegagnon fez uma rápida viagem até o Cabo Frio e informou-se de tudo o que era necessário para organizar uma base naval e militar na Guanabara. De volta, motivou armadores e cortesãos para obter financiamento de uma importante expedição ao Brasil. O rei Henrique II designou-o para uma missão que não quis especificar com clareza e não lhe deu nenhum título novo além do que já detinha, isto é, de Vicealmirante da Bretanha. Por isso, é fantasioso o titulo de Vice-rei do Brasil que alguns historiadores e romancistas lhe atribuíram. Seus grandes biógrafos franceses Heulhard e Peillard chamaram-no generosamente de Roi d'Amérique e de Vice-roi du Brési, o que não é exato.

Villegagnon chegou à Guanabara a 10 de novembro de 1555, com uma tripulação muito heterogênea de 600 homens e sua missão era exclusivamente militar e comercial, isto é: construir uma forte base naval para dar apoio ao já intenso e lucrativo tráfego comercial entre os portos franceses da Mancha e a costa brasileira. Como segundo objetivo a médio prazo, Villegagnon pretendia atacar os navios portugueses e espanhóis que voltavam das Índias, carregados de especiarias, e do Rio da Prata, com o ouro do Peru e a prata da Bolívia.

Os navegadores franceses se entendiam muito bem com os indígenas, que os apoiaram até o fim. Preparavam os toros de pau-brasil e acaju, aprisionavam papagaios, araras e micos, estocavam pimenta e ficavam à espera da chegada das naus francesas. Os franceses traziam tecidos de cores vivas, machados, facas, espelhos, anzóis, quinquilharias em geral, que eram trocados pelos produtos da terra brasileira. $\mathrm{O}$ almirante cultivou a amizade dos indígenas e do seu chefe Cunhambebe. Ele tomava aulas diárias de tupi e chegou a completar um dicionário tupi-francês que iniciara com André Thevet. Ele era 
muito mais compreensivo com as faltas dos indígenas selvagens do que com os erros de seus turbulentos franceses, chamados pelos índios de "papagaios amarelos", porque falavam muito e tinham cabelos louros.

Villegagnon começou por construir o forte Coligny na ilha que hoje leva o seu nome e agora abriga a nossa Escola Naval. Para edificar essa fortaleza contou com o apoio voluntário dos indígenas, chefiados pelo legendário chefe indígena Cunhambebe, de quem se fez amigo. Escolheu a praia do Flamengo, defronte à ilha, como base de operações em terra e lá fundou, no início de 1556, em homenagem ao rei francês Henrique II, a povoação de Henriville, ao lado da foz do rio Carioca, que hoje corre debaixo da Rua Barão do Flamengo. Esse pequeno rio teve importância fundamental para a França Antártica, pois fornecia água o ano inteiro para o forte Coligny e para as centenas de habitantes de Henriville (franceses e indígenas) que trabalhavam na construção da fortaleza e nas plantações vizinhas.

Henriville foi a primeira aglomeração urbana européia na baía da Guanabara, o que dá a Villegagnon a primazia na região. Entretanto, não se lhe pode atribuir o título de fundador da cidade do Rio de Janeiro. Henriville durou apenas quatro anos, sendo arrasada por Mem de Sá, em março de 1560, por ocasião do ataque da grande esquadra portuguesa contra 0 forte Coligny. Henriville não teve continuidade como povoação e seu marco de fundação desapareceu. A $1^{\circ}$ de março de 1565, Estácio de Sá fundou a cidade do Rio de Janeiro na Urca e, depois da expulsão definitiva dos franceses, em 1567, ela foi transferida para o morro do Castelo.

Até pouco tempo atrás ainda havia alguns autores com dúvidas sobre a existência de Henriville, pois não se encontraram vestígios dela. Em verdade a povoação está registrada em vários mapas da época, foi mencionada na carta de Villegagnon ao duque de Guise (hoje no Espaço Cultural da nossa Marinha no Rio de Janeiro) e no odioso panfleto do calvinista Pierre Richer, que pode ser consultado na Biblioteca Nacional de Paris. Lembro que a linha d'água na Guanabara, na 
praia do Flamengo, passava pelas atuais rua Senador Vergueiro, praça José de Alencar e rua do Catete. Os aterros sucessivos e as construções civis na região da praia do Flamengo sepultaram completamente quaisquer vestígios de Henriville que poderiam ser encontrados. Portanto, latu sensu, tal como Buenos Aires, o Rio de Janeiro teve dois fundadores: Villegagnon em 1556, com a sua fugaz Henriville, que não teve continuidade, e Estácio de Sá, em 1565. Os franceses estiveram na Guanabara durante mais de onze anos: de 1555 a 1567.

No início de 1557 chegaram à Guanabara doze calvinistas, enviados pelo ministro Coligny para avaliar as condições de vida no local, com vistas à possibilidade de aqui instalar uma verdadeira colônia permanente de milhares de protestantes, então perseguidos na França . Villegagnon acolheu-os bem e os calvinistas chegaram até a escrever a Calvino que ele havia abjurado a fé católica, o que era inconcebível, pois se o fizesse perderia o apoio da corte católica francesa e da Ordem de Malta. $\mathrm{Na}$ realidade, Villegagnon era um mestre no que os franceses de hoje chamam de langue de bois: ele foi propositadamente nebuloso em suas conversas com os calvinistas. Suas orações na Páscoa de 1557, tal como estão relatadas por Jean de Léry em seu famoso livro, são um modelo de embromação religiosa que nada provam. Ademais essas pretensas orações só foram publicadas em 1578, isto é, 21 anos mais tarde e na época não havia taquígrafos ou gravadores para registrá-las. Tudo indica que houve manipulação dos textos pelos calvinistas.

O historiador francês Frank Lestringant percebeu, nas atitudes de Villegagnon na Guanabara, discretas tentativas de conciliação e tolerância nas controvérsias com os calvinistas. Devemos recordar que entre as causas da Reforma, estavam o mau comportamento pessoal de alguns dos papas e a ganância do Vaticano em extorquir contribuições descabidas dos católicos, as quais representavam uma espécie de loteamento do céu. Villegagnon, no Rio de Janeiro, teria visualizado uma espécie de terceira via entre os dois movimentos religiosos em conflito. Imaginara ele uma igreja mais próxima da natureza, menos intransigente, menos preocupada com dinheiro. 
Lestringant afirma que se pode perceber com bastante clareza nos escritos de Villegagnon dos anos sessenta, depois de sua volta a Paris, essa tendência conciliadora. Notável humanista, o almirante baseava-se em Platão, Thomas Morus e Erasmo e fazia uma sutil insinuação pela reforma da administração da Igreja Católica, tão mal orientada pelo Papa, o que acabou levando aos cismas de Lutero e Calvino. Os acontecimentos na Guanabara foram uma espécie de prévia do que aconteceria na França a partir de 1562, quando explodiram as sangrentas guerras de religião, que durariam cerca de quarenta anos e só terminaram com o Edito de Nantes, em 1598.

Curiosamente, Villegagnon e Calvino foram colegas de universidade em Paris e em Orleans. Embora tenham tido divergências na mocidade, na época da implantação da França Antártica, o tom da carta que o almirante lhe escreveu da Guanabara, a 31 de março de 1557, demonstra a cordialidade de suas relações. Depois dos acontecimentos no Brasil, passaram a detestar-se e Calvino chegou até a ameaçá-lo de morte, caso aparecesse em Genebra.

Não tardou, porém, a ocorrer grave enfrentamento religioso entre o almirante e os pastores calvinistas sobre a interpretação correta da Eucaristia. No século XVI, sacava-se a espada e até se chegava a matar com o objetivo de defender, ou negar, a presença de Cristo na Eucaristia. O rompimento acabou sendo total e os calvinistas decidiram regressar à França pelo primeiro navio, uma velha nau, quase morrendo de fome e sede na viagem. Ao chegar à França, demonstraram seu ódio à Villegagnon, espalhando calúnias de todo o gênero, e com tal veemência, que o prestigio do almirante ficou abalado. Cansado de pedir reforços e dinheiro ao rei Henrique II, sem resultados, ele decidiu retornar a Paris para melhor se justificar, aproveitando seus excelentes contatos na corte.

A seguir, alguns parágrafos para comentar o livro que demonizou Villegagnon para a posteridade. Ao escrever sobre a França Antártica, o historiador deve acautelar-se para não tomar partidos, pois a tentação é considerável. Como católico e autor de um livro sobre Villegagnon, tenho a tendência de defender o 
partido católico contra o partido da igreja reformada e sempre trato de me controlar. O teste maior é analisar o apaixonado livro do editor francês residente na Suíça, Jean Crespin, sobre a morte na Guanabara dos três calvinistas condenados pelo Conselho da colônia. Conversei a respeito com o historiador Paulo Knauss, um de nossos melhores especialistas no século XVI. Disse-me ele o seguinte:

\begin{abstract}
"É preciso considerar o caráter suíço da obra. Genebra é o cantão da Suíça que emerge da luta contra a dominação francesa na época. Crespin representa claramente uma memória de afirmação da autonomia política de Genebra, construída desde o início do século XVI, quando os genebrinos conseguiram controlar politicamente o estado local. Além disso, há que se destacar nesse ambiente a importância dos editores suíços nesse contexto. Parece-me que há aí um cruzamento da memória antifrancesa e genebrina, que se constrói em torno da identidade protestante."
\end{abstract}

Antes de tudo vamos recordar a cronologia dos eventos: o terror da guerra civil-religiosa imperou na França, sobretudo nas décadas de sessenta e setenta, culminando na trágica noite de São Bartolomeu, a 24 de agosto de 1572, com o massacre de 30.000 protestantes. Villegagnon falecera em janeiro desse mesmo ano. Em 1589, o herdeiro do trono, o calvinista Henrique de Navarra, converte-se ao catolicismo e tranqüiliza a nação. Com o nome de Henrique IV, ele seria um dos mais charmosos reis da França, o Vert Galant. Em 1597, aparece o livro de Jean Créspin sobre a morte dos protestantes na Guanabara. Em1598, o Edito de Nantes instaurava a liberdade de culto na França. Terminava a guerra civil, mas os ressentimentos persistiam. Em 1610, Henrique IV, protestante convertido ao catolicismo, era assassinado pelo monge católico Ravaillac.

No final do século XVI, convinha ao partido genebrino salientar o sacrifício dos "mártires" da Guanabara e Jean Créspin foi o seu instrumento. Na realidade, o que representava na Europa a morte, justa ou injusta, de três obscuros monges- 
apóstatas em uma remota baía da América do Sul, que ninguém na época sabia exatamente onde se encontrava?

O livrinho em apreço foi escrito pelo editor Jean Créspin e publicado em Genebra, em 1597, isto é, exatamente 40 anos após os acontecimentos na Guanabara, que ele pormenorizadamente analisa em sua obra. Créspin fora também o editor da primeira edição da Viagem ao Brasil de Jean de Léry, publicado em 1578, ou seja, 21 anos depois que ocorreram os controvertidos fatos. Não se sabe exatamente quem relatou a Créspin os pormenores do julgamento e da morte dos três calvinistas. Não pode ter sido Léry quem o informou, pois seu testemunho é inaceitável, já que tais fatos aconteceram depois da partida dele e de todo o grupo calvinista no navio "Jacques", de retorno à França. O navio teve de aportar na costa brasileira porque estava fazendo muita água e tinha necessidade de ser reparado. O capitão calculou melhor suas reservas de comida e decidiu que cinco passageiros não poderiam continuar. Cinco calvinistas, da delegação chefiada pelo senhor de Du Pont, decidiram ficar no Brasil. O capitão deu-lhes um batel e dias depois, apareceram na Guanabara para grande surpresa de todos na França Antártica.

Villegagnon, que havia facilitado em tudo a partida do grupo calvinista, do qual queria se ver livre há bastante tempo, acolheu-os bem, prometeu até repatriá-los pelo primeiro navio que partisse para a França e aconselhou-os a se comportarem e não fazerem proselitismo. Eles teriam concordado, mas não tardaram a promover distúrbios e a fazer propaganda da igreja reformada. Perseguidos, tentaram fugir em direção à colônia portuguesa de São Vicente, mas Villegagnon conseguiu prender quatro deles. O quinto chegou a São Vicente, mas foi enviado à Bahia e acabou executado pelos portugueses em 1567. Os quatro calvinistas presos por Villegagnon sofreram processos de traição e deserção. Um deles, Lafont, foi absolvido pelo conselho da colônia, o que pareceria confirmar que a sentença dos demais foi justa.

Reporto-me à carta escrita da Guanabara por Villegagnon a Calvino, datada de 31 de março de 1557, na qual comunicou ao 
seu colega universitário em Paris e em Orleans (mas depois, seu inimigo mortal), o seguinte (ao final da missiva):

“... ali encontrei pessoas de quem não só não tenho nada a temer, mas também às quais posso fiar a minha vida. Tendo tal facilidade nas mãos, escolhi dez de toda a tropa, aos quais confiei o poder e a autoridade de comandar. De modo que, de agora em diante, nada se faça sem a opinião do Conselho, de tal forma que, se eu ordenasse alguma coisa em prejuízo de alguém, ficasse sem efeito nem valor, se não fosse autorizada e ratificada pelo Conselho. Todavia eu me reservei um ponto: é que a sentença tendo sido ordenada, me fosse permitido perdoar o malfeitor, de modo que eu possa ajudar a todos sem prejudicar ninguém. Eis os meios pelos quais deliberei manter e defender nosso estado e dignidade."

Este pormenor é importante, porque ele se reservou a última palavra nas decisões do Conselho, apenas para perdoar e não para mandar matar alguém, contrariando eventual decisão do dito Conselho. As palavras acima foram dirigidas a Calvino um ano antes do citado julgamento. O papa da igreja reformada, cujos seguidores mais tarde distorceram a decisão do Conselho, atribuíram a Villegagnon sozinho a culpa da condenação daqueles calvinistas que perturbavam a tranqüilidade da França Antártica.

Os debates no Conselho para esse julgamento parecem ter sido corretos, tanto que Lafont, um dos acusados, foi absolvido por falta de provas e libertado. Os três outros acusados foram condenados à morte por afogamento e executados imediatamente. Estávamos em fevereiro de 1558. Jean Crespin chamou-os de mártires, mas segundo o historiador naval Léonce Peillard (Villegagnon, Vice-Amiral de Bretagne et Vice-Roi du Brésil, edições Perrin, Paris, 1991), o seu texto é ridículo e o autor dá a impressão de que "aqueles carneirinhos foram esganados por um tirano sangüinário e alucinado", e o renomado historiador naval pergunta-se: "Enquanto Villegagnon puniu com a morte três homens por traição, quantos Calvino havia feito executar 
somente por terem opiniões diferentes da sua ?" Lembro que Calvino, em 1561, ao ler a carta enviada por Villegagnon desafiando-o para um debate público sobre o dogma reformado, enfureceu-se, pisoteou a carta e despachou o mensageiro, dizendo-lhe que se Villegagnon aparecesse em Genebra de lá não sairia vivo.

Estes seriam os fatos que realmente ocorreram na Guanabara em 1558 e foram relatados por vários outros franceses presentes à cena. O comportamento pessoal de Villegagnon aparentemente foi correto: aprovou a libertação de um calvinista contra quem não havia provas e ratificou a condenação dos três outros, que realmente eram culpados de traição, distúrbios e desobediência ao comandante-em-chefe da colônia. Em outras circunstâncias, esses fatos seriam considerados plenamente normais, já que no século XVI os chefes tinham direito de vida ou morte sobre os seus comandados. No entanto, a paixão religiosa dos reformados torceu a interpretação do julgamento dos três calvinistas e a literatura calvinista condenou Villegagnon por séculos afora. É importante sublinhar que, nos dias de hoje, não devemos julgar acontecimentos ocorridos 450 anos atrás com os parâmetros do século XXI.

Os pastores calvinistas, em publicações anônimas, apaixonadas, aparecidas na Suíça e na França, em 1561 e 1562, acusaram Villegagnon de que "ele se poluía com as índias desnudas na Guanabara", mas, surpreendentemente, Jean de Léry afirmou em seu livro que, durante a sua estada na Guanabara, ele não viu nada disso, nem teve nenhuma prova dessa acusação. Este gesto de Léry lhe faz honra, pois contradisse os pastores despeitados pelo seu fracasso na Guanabara em visível mentira, só para desmoralizar o almirante.

O grande historiador francês Frank Lestringant, um protestante moderado, em seu livro Le Huguenot et le Sauvage (Droz, Genebra, 2004) fez significativo comentário sobre a controvérsia religiosa na Guanabara: 
“... Os pastores pareciam querer conciliar o inconciliável. Em matéria de controvérsia eucarística, seu racionalismo pode seduzir, mas sua obstinação decepciona ou revolta. Estamos prontos a lamentar o destino das vítimas, mas essas vítimas do fanatismo se mostram por sua vez mais fanáticas do que seus perseguidores. (...) Seus sofrimentos merecem que nos apiedemos deles, mas seu orgulho deve ser condenado. Contra o austero e impertinente Pierre Richer, representante de Calvino e ministro da Palavra, o fulminante Villegagnon terá sempre o papel simpático." (página 12).

Em suma, o texto de Jean Crespin tem interesse histórico, mas não nos devemos deixar levar pelo rancor que os protestantes tinham dos católicos naquela época conturbada, conseqüência de uma guerra civil sangüinária que durou mais de quarenta anos e que provocou extensa destruição e a morte de dezenas de milhares de pessoas inocentes em grande parte do território francês. Aliás, aquele foi um período de que os franceses até hoje se envergonham e preferem silenciar. Importante historiador francês disse-me recentemente que a segunda metade do século XVI é o período em que há menor número de livros, teses e estudos na bibliografia francesa. $O$ texto de Crespin transpira esse ódio, compreensível até certo ponto, mas devemos dar-lhe um desconto, pois seu texto reflete todos os sacrifícios e violências que seus correligionários sofreram durante aquele período terrível. Por isso tudo, o Rei de Navarra, o futuro Rei Henrique IV, decidiu converter-se ao catolicismo porque, afinal de contas, "Paris bem vale uma missa"...

$\mathrm{Na}$ ausência de Villegagnon, em 1560, o governador Mem de Sá chegou à Guanabara com uma grande esquadra. Bombardeou o forte Coligny durante vários dias, arrasou Henriville e acabou por derrotar os franceses, pouco numerosos, que se refugiaram no morro da Glória. No entanto, ele só teria conseguido penetrar na fortaleza com o auxílio de um traidor francês, Jean Cointat, que depois foi preso e enviado para Lisboa, julgado e exilado para Goa, onde veio a falecer. $\mathrm{Na}$ 
França, Villegagnon já havia reunido gente e material para uma nova expedição, quando recebeu a notícia da queda do forte Coligny. Acabou desistindo e ainda recebeu a vultosa indenização de 3.000 ducados dos portugueses, que queriam vêlo longe do Brasil.

A respeito da controvertida tomada do forte Coligny, cito o especialista Paul Knauss:

“...parece bom destacar o fato de que os franceses não sobrevalorizam a batalha de 1560, enquanto os portugueses se contrapõem a isto. Trata-se de um combate pelo fato, pois as versões estão sempre sendo reconstruídas. Talvez fosse uma possibilidade apenas sublinhar o contraste das proporções e assim o bom leitor saberá medir que o realmente acontecido ficou entre o minimalismo francês e o exagero lusitano. Mas chamo atenção para a gravura de Thevet do combate. É a imagem de uma grande batalha. Isso pode ser uma pista para admitirmos que considerando as proporções da época e do mundo colonial, certamente a batalha foi grande. E se considerarmos o envolvimento das forças indígenas, aí então teremos outra proporção. (...) Certo é que Jean Cointat auxiliou os portugueses no combate, indicando o único local de acesso à fortaleza, as condições das forças francesas e fornecendo-lhes descrições da ilha e do arsenal."

Ao regressar do Rio de Janeiro em 1559 para justificar-se das acusações que lhe fizeram os calvinistas despeitados pelo seu fracasso na Guanabara, Villegagnon conseguiu explicar satisfatoriamente o que ocorrera no Brasil. Convenceu os grandes da corte que sempre o haviam apoiado, como Maria Stuart, ora rainha da França e esposa do rei Francisco II, a depois rainha regente Catarina de Médicis, o duque de Guise, o cardeal de Lorena e o condestável de Montmorency. Redigiu vários pequenos livros rebatendo os anônimos insultos e infâmias dos calvinistas que o assediavam. Desafiou seus examigos e depois inimigos mortais Calvino e Gaspard de Coligny a debates públicos sobre os dogmas da religião reformada, o que eles recusaram. A Ordem de Malta, na pessoa do grão-mestre 
Parisot de la Valette, seu imediato na aventura do seqüestro de Maria Stuart, elevou-o à diretoria da Ordem e concedeu-lhe a rendosa comandaria de Beauvais-en-Gatinais, perto de Nemours, onde residia em bela casa fidalga.

No final de sua vida, Villegagnon teve papel importante nas lutas religiosas francesas. Participou do cerco de Rouen (onde foi ferido), comandou a defesa de Sens e de Auxerre, derrotando as tropas protestantes muito mais numerosas do príncipe de Condé. Apesar das calúnias espalhadas pelos calvinistas, Villegagnon morreu prestigiado pela Ordem de Malta, que, em 1570, designou-o como seu Embaixador junto à corte francesa de Carlos IX. Villegagnon faleceu como um bom burguês na sua cama em Plombières, em 1572, meses antes da terrível noite de São Bartolomeu. Não chegou a saber que seu arqui-inimigo Coligny foi assassinado e jogado no rio Sena, nu e pendurado pelos pés. Tampouco chegou a ler o livro de Jean de Léry, publicado seis anos depois de sua morte. Se ainda estivesse vivo, certamente o contestaria veementemente, como era seu feitio.

A vida e os feitos de Villegagnon depois de seu regresso do Brasil refutam amplamente as pretensas maldades que ele teria cometido no Brasil, segundo os cronistas calvinistas, e em nada afetaram seu prestígio junto às mais altas autoridades católicas da França. Provavelmente alguns desses fatos, se realmente ocorreram, não tiveram maior gravidade. Na realidade, no Brasil ele foi demasiado rigoroso com a sua turbulenta tripulação, em parte retirada das prisões do norte da França. Como cavaleiro de Malta, estava habituado à rígida disciplina da Ordem e aqui agiu com mão forte. Errou, porém, ao não trazer para o Brasil muitas mulheres em sua expedição, para aqui se casarem com os jovens colonos franceses, que se atiraram às belas índias desnudas. Esse esquecimento lhe causaria sérios problemas de disciplina, que reprimiu severamente.

Os cronistas calvinistas foram implacáveis com a sua memória e repetiram incansavelmente as acusações contra Villegagnon por séculos a fio. Depois da publicação do belo livro de Leonce Peillard, em 1991, quase tudo parece esclarecido. Por 
isso, a Marinha de Guerra brasileira prestou recentemente ao grande marinheiro francês significativa homenagem em sua cidade natal, Provins. Por feliz iniciativa do almirante Max Justo Guedes, então diretor do Serviço do Patrimônio da Marinha, o navio-escola brasileiro levou até Rouen um pequeno obelisco construído com pedras retiradas da ilha de Villegagnon, na Guanabara, e lá foi erguido, a $1^{\circ}$ de agosto de 2000 , em comovente cerimônia a que compareceram o prefeito da cidade, o Embaixador do Brasil e autoridades da Marinha da França. O comandante Lucien Provençal, meu parceiro no livro sobre a França Antártica e hoje sócio correspondente do IHGB, foi um dos oradores nessa cerimônia em Provins.

Os festejos do centenário do descobrimento do Brasil ensejaram várias iniciativas em torno da França Antártica. Em 2000, o autor destas linhas e Lucien Provençal publicaram o livro Villegagnon e a França Antártica - uma reavaliação, que teve boa acolhida da grande imprensa brasileira, e uma edição francesa foi publicada em Paris em 2002. Em dezembro do mesmo ano, o Espaço Cultural da Marinha no Rio de Janeiro apresentou importante exposição intitulada "Villegagnon e a França Antártica", no quadro das comemorações dos 500 anos do Descobrimento. Afinal, se fazia justiça no Brasil ao ilustre cavaleiro de Malta.

Curiosamente, o tema da França Antártica atraiu até a atenção mundial. Em 2001, o escritor francês Jean Christophe Rufin recebeu o Prêmio Goncourt em Paris por seu romance Rouge Brésil, que se passa na França Antártica. O livro alcançou imenso sucesso e já vendeu mais de meio milhão de exemplares no mundo inteiro. A fértil imaginação do romancista criou vários episódios que não têm fundamento. Como bom francês, o escritor preferiu dar ao traidor Jean Bolès, a nacionalidade italiana. A descrição da tomada do forte Coligny beira o inverossímil, com Mem de Sá matando o traidor ajoelhado perante o padre José de Anchieta, que parece abençoar o ato! Seu tratamento do personagem Villegagnon também deixou um pouco a desejar, embora não tenha chegado a reproduzir as caluniosas acusações dos calvinistas. Em 2003, outro escritor 
francês, Serge Elmalan, publicou em Lausanne, Suíça, o livro Villegagnon ou l'Utopie Tropicale, outro romance baseado na França Antártica, que não teve a mesma publicidade, mas que certamente está muito mais perto da verdade histórica da aventura francesa na Guanabara do que a obra de Rufin. Ambos os livros já estão publicados em português no Brasil.

Nosso conhecido romancista Antônio Torres é autor de um saboroso pequeno livro intitulado Meu Querido Canibal, que também transcorre na França Antártica e focaliza o pitoresco chefe indígena Cunhambebe, amigo de Villegagnon. Finalmente, lembro a publicação da $2^{a}$ edição da biografia romanceada de Villegagnon de autoria do escritor Chermont de Brito, intitulada Villegagnon, o Rei do Brasil, com apresentação e notas elaboradas por mim, à luz dos novos documentos descobertos recentemente.

Em 2003, o Serviço Histórico da Marinha Francesa organizou em Toulon importante base naval do sul da França, uma bela mostra sobre a França Antártica, organizada pelo Comandante Lucien Provençal, acima mencionado. Para o ano corrente, com o objetivo de comemorar os 450 anos da chegada de Villegagnon à Guanabara a 10 de novembro de 1555, o Museu Histórico Nacional decidiu em boa hora organizar o presente seminário sobre "O Universo da França Antártica". Finalmente, a Fundação Darcy Ribeiro vai publicar em 2006 importante volume com 22 cartas de Villegagnon, mais as duas cartas de seu secretário Nicolas Barré, inéditas no Brasil, e ainda o faccioso livrinho de Jean Crespin, com apresentação e comentários meus. Last but not the least, uma segunda edição revista do meu livro sobre a França Antártica, em parceria com o comandante Lucien Provençal, acaba de ser lançada pela Nova Fronteira.

Acrescento em seguida algumas informações preciosas para quem quer estudar a França Antártica mais profundamente. Os registros da montagem da expedição são muito esparsos. Sua repercussão no século XVI europeu povoou a literatura da época, marcando, por exemplo, a obra do famoso poeta clássico francês Ronsard, bem como o humanismo de 
Montaigne, no seu famoso livro de Ensáios. Algumas dessas edições podem ser encontradas em exemplares raros na Biblioteca Nacional do Rio de Janeiro. Agora a nova publicação da Fundação Darcy Ribeiro sobre a França Antártica reproduz as cartas publicadas por Paul Gaffarel, e outras mais que consegui descobrir em outras edições. Outros documentos de interesse podem ser encontrados nas excelentes obras de Arthur Heulhard, em 1897, e de Leonce Peillard, publicada em Paris em 1991, que foram de tanta valia para a elaboração do meu citado livro. Saliento finalmente a $3^{\mathrm{a}}$ edição do excelente livro de Frank Lestringant intitulado Le Huguenot et le Sauvage, (Genebra, 2004), de notável erudição.

Contudo, a França Antártica do século XVI possui uma característica que marca seu universo de fontes. Os personagens envolvidos em seu desenrolar foram homens de saber. Além disso, as querelas religiosas impuseram uma disputa de argumentos, o que se combinou com a tarefa assumida pelos huguenotes de detratar publicamente Villegagnon. Isto os levou a produzir textos agressivos, forçando Villegagnon a publicar libelos contrários em resposta. Os famosos livros de André Thevet, Singularidades da França Antártica, e de Jean de Léry, História de uma viagem feita ao Brasil, tiveram várias edições na Europa e no Brasil. O livro menos conhecido é o de Marc Lescarbot, dedicado principalmente ao projeto colonizador francês na Flórida nos anos de 1570, também fracassado, mas que contém um capítulo interessante sobre o episódio da França Antártica do qual o autor também foi personagem.

Encontra-se na Divisão de Obras Raras da nossa Biblioteca Nacional a conhecida obra fundadora da memória protestante francesa na Europa - a raríssima História dos Mártires, de Jean Crespin, acima comentada. A Fundação Darcy Ribeiro vai republicar essa obra, em seu livro sobre a França Antártica, com comentários meus. Em contraposição, encontramos também no acervo da mesma divisão da FBN uma das defesas públicas de Villegagnon, respondendo em forma impressa às acusações que sofrera por parte dos seus anônimos detratores. 
De resto, no rol dos autores franceses, é preciso citar ainda um pequeno opúsculo de Jean Cointat, personagem que se aliou aos portugueses, e que terminou enredado nas teias da Inquisição lusitana na América, cujo processo foi publicado pelos Anais da Biblioteca Nacional, e seu original está depositado no Arquivo Nacional da Torre do Tombo, em Lisboa.

No conjunto, destacam-se especialmente as notas de Manuel da Nóbrega e de José de Anchieta, que não se restringem apenas à correspondência, mas incluem outros textos ricos em elementos que dão sentido às representações religiosas da ação francesa na América portuguesa. Esse ponto de vista religioso pode ser enriquecido ainda pela consulta ao Primeiro Livro de Reconciliações e Confissões da Primeira Visitação do Santo Ofício da Inquisição das partes do Brasil, datado de 1591 e cuja transcrição faz parte do acervo da Divisão de Manuscritos da Biblioteca Nacional do Rio de Janeiro. Essa peça histórica acerca da vida no mundo colonial quinhentista reúne informações sobre três franceses arrolados pela Inquisição e estabelecidos na América portuguesa. A confissão de Pero de Vila Nova é a mais importante relacionada diretamente com a França Antártica, personagem que repete a trajetória de João Cointat.

Nos Anais da Biblioteca Nacional do ano de 1906 encontrase, ainda, o mais importante registro oficial da parte portuguesa sobre a França Antártica, que são os documentos do governador-geral do Brasil da época, Mem de Sá, comandante militar português de 1560. São curiosas as opiniões do governador em relação aos franceses e a Villegagnon, que ele elogia como excelente organizador, louvando até os indígenas treinados pelos franceses como "bons espingardeiros". Aliás, Mem de Sá foi repreendido pela rainha regente de Portugal por não haver perseguido os franceses depois da vitória, os quais se refugiaram no morro da Glória e na ilha do Governador e lá ficaram até 1567.

Como salientou Knauss, é preciso apontar que as crônicas dos componentes da França Antártica são conhecidas através de suas estampas que nos dão a imagem que o europeu tinha do 
Novo Mundo. Estas gravuras constituem por si só um corpus documental interessante e que permite abordar a história da imagem e da edição. As ilustrações do livro de André Thevet permitem acompanhar as bases do povoamento francês, como o trabalho de corte do pau-brasil.e a localização de Henriville no mapa da Guanabara. Embora nesse caso, sua imagem forneça um dos poucos registros do estabelecimento francês, ainda assim a inventividade das suas imagens serve para fornecer um retrato do Novo Mundo.

Por sua vez, nem sempre o próprio autor pode ser responsabilizado pelo caráter inventivo das imagens da vida no continente americano. As estampas ilustrativas nem sempre foram fiéis aos autores das crônicas, sendo criação dos editores ou dos gravadores que recebiam encomendas. Assim é que na crônica de Jean de Léry, a montanha do Pão de Açúcar aparece como se estivesse numa ilha, indicando um claro desconhecimento da terra por parte do desenhista, mas certamente não do personagem testemunho. Esse exemplo ilustra como a obra impressa na Época Moderna, nos primórdios da história da imprensa, muitas vezes autonomizava o livro em relação ao seu autor.

Vemos assim que os 450 anos da França Antártica foram devidamente homenageados e devemos rejubilarmo-nos pelos merecidos festejos da efeméride, centralizados no seminário do Museu Histórico Nacional.

MARIZ, Vasco. Villegagnon: Hero or Villain? História, v.27, n.1, p.51-76, 2008.

Abstract: Villegagnon is one of the characters most massacred in our colonial history. The reason for this was the frequently reedited book, Travel to the Land of Brazil by Jean de Lery, as well as the History of Martyrs by Jean Crespin, both found among the historians. Villegagnon is portrayed as the villain. Recently in 1991, the naval historian, Leonce Peillard, published in Paris a book entitled Villegagnon, the Vice-admiral of Britanny and Viceroy of Brazil (Perrin Editions) that showed convincing recent 
research explaining and absolving Villegagnon of the Calvinists' accusations. After this, the Brazilian Navy decided to pay homage to Villegagnon and in the year 2000, the Brazilian ambassador in France raised an obelisk made of stones from the Island in Provins, his birthplace, near Paris. The French admiral is considered by many historians as the true founder of Rio de Janeiro and not Estacio de Sa, who only arrived in Guanabara eleven years later.

Keywords: Villegagnon; French Colonization; Estacio de Sa.

\section{BIBLIOGRAFIA SELETA \\ Na França:}

BARRÉ, Nicolas - Discours sur la navigation du chevalier de Villegagnon em Amérique, editor Le Jeune, Paris, 1558.

BOUYER, Marc e DUVIOLS, Jean Paul - Le Theatre du Nouveau Monde - Les Grands Voyages de Theodore Bry, Documents Gallimard Album, Paris, 1992.

CLOULAS, Ivan - Henri II, edições Fayart, Paris, 1985.

COTTRET, Bernard - Calvin., Paris 1986.

CRESPIN, Jean - Histoire des martyrs, persecutez et mis à mort pour la verité de l'Evangile depuis le temps des apôtres, Genebra, 1597.

DUCHEIN, Michel - Marie Stuart, edições Fayart, Paris, 1987.

ELMALAN, Serge - Villegagnon ou l'Utopie Tropicale - Éditions Favre, Lausanne, 2002.

FRASSER, Antonia - Marie Stuart, reine de France et d'Écosse, edições Laffont, Paris, 1973.

GAFFAREL, Paul - Histoire du Brésil Français au XVI siècle, Maisonneuve, Paris, 1878. [Reproduz duas cartas de Nicolas Barré e dezoito de Villegagnon. Dedicado a D. Pedro II.]

GUÉRIN, Leon - Les navigateurs français, Paris, Morizer, 1847.

HATTON, Padre Claude - Mémoires contenant le récit des évenements accomplis de 1553 à 1582, Imprimerie Impériale, 2 volumes, Paris,1857. HEULHARD, Arthur - Villegagnon, roi d'Amerique, un homme de mer au XVI siècle, edições Leroux, Paris, 1897.

JULIEN, André - Les Voyages de découverte et les premiers établissements, Paris, 1948.

LENOIR, A - Les Provinois celèbres (1886). 
LÉRY, Jean de - Histoire d'un voyage au Brésil, edições Le Livre de Poche, Paris, 1995.

LESTRINGANT, Frank - Le Huguenot et le Sauvage, edições Droz, Genebra, 2004.

MARAN, René - Nicolas Durand de Villegagnon, edições France Empire, s/d, Paris.

MEYLAN, Auguste - Vie de Gaspard de Coligny, Amiral de France, editor C.Neyrueis, Paris, 1862.

MIQUEL, Pierre - Les guerres de religion, edições Fayard, Paris, 1987. PEILLARD, Leonce - Villegagnon, vice-amiral de Bretagne, vice-roi du Brésil, edições Perrin, Paris, 1991. Prefácio de Allain Peyrefitte.

RAEDERS, George - Échanges et rapports: la Bretagne, le Portugal et le Brésil, Université de Haute Bretagne, vol. II, Nantes, 1977.b RICHER, Pierre (?) - Contre les exécrables impostures, impietés et blasphèmes de Durand, bordelier qqui se nomme Villegagon. Panfleto de 8 páginas distribuido em Paris em 1561, sem nome do autor, do editor e do local de publicação. Pode ser consultado na Bibliothèque Nationale de France, em Paris. Outra edição teve o título de Réfutations des folles rêveries, exécrables blasphèmes, erreurs et mensonges de Nicolas Durand qui se nomme Villegagnon.

RUFIN, Jean Christophe - Rouge Brésil, Éditions Gallimart, Paris, 2001. Romance.

THEVET, André - Les singularitez de la France Antarctique, edições Le Temps, Paris, 1982.

Les Français en Amérique, Paris, P.U.F, 1953.

VERTOT, abbé de - Les Chevaliers de Malte, século XVIII.

VILLEGAGNON, Nicolas Durand de - Caroli V Imperatoris in Africam

ad Argieram. Parisiis, Ioannem Roygni, uia ad D. Iacobum, 1542. De belo Melitensi, \& eius euentu Francis imposito, ad Carolu

Caesarem V. Parisiis, $\quad$ Carolum Stephanu, 1553. Não paginado.

Response avx libelles d'injures publiez contre le cheualier de Villegaignon. Au lecteur Chrestien. A Lion, par Benoit Rigavd, 1561. Estrille povr blason d'armoiries de la Cheaullairie de Villegaignon. Paris [s. ed.] 1561. Relation de l'expédition de Charles-Quint contre Alger. Suivie de la trad. du texte latin par Pierre Tolet. Publiées par H. D. de Grammont. Paris, Auguste Aubry; Alger, Juillet St. Larger, 1874. Propositions contentieuses entre le chevalier de Villegagnon et

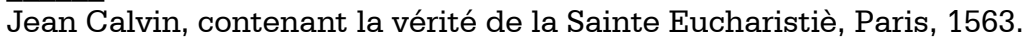


No Brasil:

ALMEIDA, Candido Mendes de - Notas para a história pátria - a catástofre de João Bolès foi uma realidade ?, na revista do IHGB, tomo XLII, parte 1, 1879, páginas 141 a 205.

ABREU, Capistrano de - Capítulos de História Colonial, $5^{a}$ edição, Briguiet, 1969, Rio de Janeiro. Revisão de José Honório Rodrigues. ANCHIETA, José de - Cartas ao Padre Geral de São Vicente, EDUSP Itatiaia, 1988. Páginas 169 e 170.

ANCHIETA, José de - De gestis Mendi de Saa, Fundação Biblioteca Nacional, Rio de Janeiro, 1997. Introdução de Paulo Roberto Pereira. ANDRADE, Leoncio Caldeira de - A igreja dos fiéis (Coligny no feudo de Villegagnon), editora Centro Brasileiro de Publicidade, Rio de Janeiro, 1947.

BARBOSA, Mario Lima - Les français dans l'histoire du Brésil, Briguiet, Rio de Janeiro, 1923.

BARDI, Claudio - O Rio de Janeiro em seus 400 anos, Rio de Janeiro, 1965.

BELCHIOR, Elysio de Oliveira - Conquistadores e povoadores do Rio de Janeiro, Livraria Brasiliana, Rio de Janeiro, 1965.

BONNICHON, Philippe - História Naval Brasileira, $1^{\circ}$ volume, Rio de Janeiro, 1975, Ministério da Marinha.

BULCÃO, Clovis - A quarta parte do mundo (romance), Nova Fronteira, Rio de Janeiro, 1999.

CALMON, Pedro - História do Brasil, $1^{\circ}$ volume, Editora José Olimpio, Rio de Janeiro, 1959. Contém bela gravura da ilha de Serigipe.

COROACY, Vivaldo - Memórias da cidade do Rio de Janeiro, Editora José Olympio, Rio de Janeiro,1965.

CORTESÀO, Jaime (org.) - Pauliceae Lusitana Monumenta Historica, Real Gabinete Português de Leituira do Rio de Janeiro, 3 volumes, 1956.

COSTA, Othon - A fundação do Rio de Janeiro, Centro Carioca, Rio de Janeiro, 1939.

CRESPIN, Jean - A Tragédia da Guanabara, ou a história dos protomártires do cristianismo no Brasil, Rio de Janeiro, Tip. Pimenta de Melo, 1947.

CRULS, Gastão - Aparência do Rio de Janeiro, Editora José Olympio, Rio de Janeiro, 1965.

BRITO, Chermont de - Villegaignon, o Rei do Brasil, editora Francisco Alves, Rio de Janeiro, 1985. $2^{\mathrm{a}}$ edição, 2002, com.apresentação e notas de Vasco Mariz. 
ELMALAN, Serge - Villegagnon ou a Utopia Tropical, Rio de Janeiro, 2004.

FERREZ, Gilberto - O Rio de Janeiro e a defesa do seu porto, Rio de Janeiro, 1972, 2 volumes.

FONTES, Ofélia e Narbal - Um reino sem mulheres, Rio de Janeiro, Editora José Olympio, 1986 Romance biográfico de Villegagnon. FRAGOSO, Augusto Tasso - Os franceses no Rio de Janeiro, Biblioteca do Exército, Rio de Janeiro, 1950. Nova edição 2005 com apresentação de Vasco Mariz.

FROTA, Guilherme de Andréa - Os franceses e a fundação do Rio de Janeiro, Universidade Católica, Rio de Janeiro, 1963.

GALVÀO, Barão Ramiz - João Cointha - comentário sobre João Bolès ou João Cointha, na revista do IHGB, tomo 102, volume 156, página 570.

Instrumentos de Serviço de Mem de Sá, anais da Biblioteca Nacional, Rio de Janeiro, n 27; 1905.

JORGE, A.G . de Araujo - O Brasil e a França no século XVI, na revista do IHGB, volume 77, parte II, páginas 193 e 194..

LÉRY, Jean de - Viagem à terra do Brasil, edição da Biblioteca do Exército, Rio de Janeiro, 1961. Outras edições pela Editora Itatiaia, Belo Horizonte, 197, pela Fundação Darcy Ribeiro, Rio de Janeiro, 2006. MELLO FRANCO, Afonso Arinos de - O índio e a revoluçào francesa, Editora José Olimpio, Rio de Janeiro, 1930.

MENDONÇA, Paulo Knauss - O Rio de Janeiro da Pacificação, Biblioteca Carioca, vol.18, 1991.

NOGUEIRA, Manuel Tomás Alves - Villegagnon, coleção Epasa, Biblioteca Brasileira de Cultura, Rio de Janeiro, 1944, Prefácio de Basilio de Magalhães.

PINHEIRO, J . C . Fernandes - A França Antártica, na revista do IHGB, volume 22, 1859, páginas 3 a 134.

Processo de João Bolès e justificação requerida nos anais da Biblioteca Nacional $n^{\circ} 25$, Rio de Janeiro, 1903.

ROCHA PITA - História da América Portuguesa, edição EDUSP/Itatiaia, Belo Horizonte, 1976.

ROCHA POMBO, José Francisco da - História do Brasil, volume 1, editora Jackson, Rio de Janeiro, 1935.

SALVADOR, Frei Vicente do - História do Brasil, Rio de Janeiro, 1889.

SENNA, Nelson - Os Protestantes no Brasil. 
SOUSA, Augusto Fausto de - A baía do Rio de Janeiro, sua história e descrição de suas riquezas, Tipografia militar Costa Santos, $2^{\mathrm{a}}$ edição, Rio de Janeiro, 1882.

TAVARES, Aurélio de Lyra - Brasil-França ao longo de 5 séculos, Biblioteca do Exército, Rio de Janeiro, 1979.

TEIXEIRA, Filho Álvaro - Roteiro Cartográfico da Baía da Guanabara e cidade do Rio de Janeiro - Séculos XVI e XVII, Livraria São José, 1975, Rio de Janeiro.

TROTA, Frederico - A Fundação do Rio de Janeiro, Secretaria de Estado de Educação e Cultura, coleção cidade do Rio de Janeiro, $n^{\circ} 6$, s/d.

VARNHAGEN, Francisco Adolfo - História Geral do Brasil, editora Melhoramentos, tomo 1, 4ª edição, São Paulo, 1948.

VIANNA, Hélio - História do Brasil, edição Melhoramentos, São Paulo, 1980.

VILLEGAGNON, Nicolas Durand de. Carta a Calvino, na Revista do Instituto Histórico e Geográfico Brasileiro, Rio de Janeiro, 1840, páginas 198 a 202.

WEHLING, Arno e WEHLING, Maria José - Formação Colonial do Brasil, Nova Fronteira, Rio de Janeiro, 1994.

\section{Na Alemanha:}

NOGUEIRA, M.T. Alves - Der Mönchritter Nikolaus von Villegagnon, edição do Brockhaus de Leipzig, 1887. Republicado em português em 1944.

\section{Na Inglaterra:}

HEMMING, John - Red Gold, the Conquest of the Brazilian Indians, McMillan, Londres, 1978.

SOUTHEY, Robert - History of Brazil, Longman, Londres, 3 volumes, 1810-1819. Tradução brasileira publicada pela EDUSP/Itatiaia, Belo Horizonte, 1981, 2 volumes.

\section{Na Itália:}

VILLEGAGNON, Nicolas Durand de - Ad articulos Calvianae de sacramento eucharistiae traditionis. Gasparem Bindonum, Veneza, 1562. 
Em Portugal:

BOULES, Jean Cointat - Paradoxo ou sentença filosófica ? , Lisboa, 1566.

COUTO, Jorge - A construção do Brasil, edições Cosmos, Lisboa, 1995. SERRÃO, Joaquim Verissimo - O Rio de Janeiro no século XVI, estudo histórico, Lisboa, 1961, edição da Comissão Nacional das

Comemorações do IV Centenário do Rio de Janeiro, volume 1.

Artigo recebido em 03/2008. Aprovado em 07/2008. 
